An empirical investigation of users' perceptions of web-based communication on a construction project

Sherif Mohamed, and Rodney A. Stewart

Elsevier BV. Automation in Construction: an international journal for the building

industry, 0926-5805. 12 pp. 43-53, 2003.

\title{
An empirical investigation of users' perceptions of web-based communication on
}

\section{a construction project}

\begin{abstract}
Information is the cornerstone of any business process. It is not surprising, therefore, for IT to emerge as a key enabler that changes the way business is conducted. During the last decade or so, significant productivity improvements experienced by a wide range of industries have been associated with IT implementation. IT has provided these industries with great advantages in speed of operation, consistency of data generation, accessibility and exchange of information. This paper details an empirical investigation of users' perceptions of a web-based communication tool adopted on a large construction project. A questionnaire-based research approach was adopted for this purpose. The questionnaire aims to solicit user perceptions of web-based communication to highlight its role in enabling improved project information management and business relationships, compared to the prevailing business-as-usual level.
\end{abstract}

Keywords: Information technology, performance measurement, information exchange, construction projects

\section{Introduction}

The majority of construction business processes are heavily based upon traditional means of communication such as face-to-face meetings and the exchange of paper documents in the form of technical drawings, specifications and site instructions. The need to increase the efficiency of these processes via exchanging massive volumes of information at high speed and at relatively low cost has been long recognised by the industry [1]. However, the use of Information Technology (IT) in construction has not progressed to the level that can be seen in other industries [2]. This is due to a number of historical, industrial and market forces that perpetuate the industry's culture, thus affecting the extent of IT adoption in day-to-day business processes [3]. 
Defining the scope and boundaries of the use and performance of IT in construction is difficult due to the relatively limited amount of detailed research that has been carried out in the field [4]. To many, IT in construction encompasses the use of all electronic means of information transfer (computer networks, local area networks LANs, Internet, mobile phones, faxes, etc.) Others see IT as the use of the latest technology, such as, knowledge-based systems, computer-based decision support systems, and object-orientated CAD, while others see it as part of management strategies and concepts of concurrent engineering, just-in-time production and process re-engineering. This diversity has led to a number of different IT definitions. This paper adopts an information-centric definition which encompasses the use of electronic machines and programs for the collection, processing, storage, transfer and presentation of information. This is to demonstrate the key role IT plays in improving the effectiveness of communication and information exchange in the context of managing a construction project.

As international competition continues to intensify, significant numbers of construction organisations are strategically investing large amounts in IT as they seek to gain competitive advantage [5]. Despite the welldocumented high expectations of improved responsiveness, efficiency and control of construction-related business operations [6], many of these organisations are dissatisfied by their IT investments [7]. This dissatisfaction is in part due to the difficulty in measuring operational benefits [8] leading to some concerns about the payoff from investments in IT [9]. In an attempt to evaluate IT-induced improvement on construction projects, this paper details the results of an empirical investigation about users' perceptions of a web-based tool used, for the first time, to instantly share, visualise and communicate project information between project participants. The developed questionnaire survey aims to gauge the interests of key stakeholders (eg. managers, engineers, architects, employees etc.) across five (5) IT-related performance perspectives. Each perspective consists of a diverse set of identifying questions (items) which focus on individual aspects where IT-induced improvement may arise. 


\section{Information Exchange in Construction Projects}

The need for improved project communication is a widely documented issue in the construction industry. To facilitate the management of project information and address project communication requirements, a number of IT tools have been used with the aim to maximise benefits and reduce cost for the entire project team. The key to project information management, though, consists of the information flows associated with interorganisational communications [10]. As a result, a core issue is the effective management of information, both in the form of information flows that permit rapid inter-organisational transactions between project participants, and in the form of information accumulated, coded, and stored in firm database structures.

The construction industry has for many years suffered from difficult-to-access, out-of-date and incomplete information [11]. Until the very recent past, it would have been inconceivable to electronically control and direct information flows in construction. Documents can now be produced and transmitted instantaneously by digital transmission at fractions of their previous costs. Electronic Data Interchange (EDI) permits computers and information systems to communicate directly with other computers, strengthening joint operations among organisations. Unfortunately, the effectiveness of utilizing IT in a construction project could be hindered by the inability to share data in electronic form between project partners. Although it is not practical to expect compatibility between all information systems in the short term, there should be more focus on the standardisation of interfaces between the different systems. IT tools should be able to exchange digital information with other applications/systems using appropriate data exchange standards [12].

At the project level, which is the basic operating level in construction, project information is usually considered as the processed and presented data in a given situation, and is the data that enables effective action [13]. Information produced by many sources, at many levels of abstraction and detail and retained by the creator of that information contributes to fragmentation of the industry [14]. Therefore, timely and accurate information is important for all project participants as it forms the basis on which decisions are made and physical progress is achieved. Wasted time and cost in construction projects can be traced back to 
poor coordination caused by less than optimum information handling and exchange, inadequate, insufficient, inaccurate, inappropriate, inconsistent, late or a combination of them all [3].

Traditionally, project Information Exchange (IE) between designers and contractors has been mainly based on paper documents [15]. These documents come in the form of architectural and engineering drawings, specifications, and bills of quantities and materials. This practice is far from being satisfactory, with research showing that about two-thirds of the construction problems being caused by inadequate communication and exchange of information and data [16]. Research [17] has also noted that $85 \%$ of commonly associated problems are process related, and not product related. These findings explain the growing awareness of the value of IT to bring together the major parties in the construction process, and share project as well as industry information in a meaningful way.

The relationship between construction project participants is normally complex and involves many parameters that extend across technical, functional, business, and human dimensions. As a result, attention and focus must be given to the intensive collaboration among project participants to synchronise both the input and output of the supply chain. Undoubtedly, a key enabler to successful collaboration is the ability to communicate, and share and exchange project information in a timely and accurate manner. A recent European survey [18] has highlighted the need for electronic sharing of information between Large Scale Engineering (LSE) clients' information systems and those of:

- Funding bodies in the areas of finance and accounting;

- Consultants in the areas of modelling and calculations;

- Project Managers in the areas of project planning and QA systems \& documents control;

- Contractors in the areas of CAD drawings, materials procurement, project planning, QA systems \& documents control, and communication systems; and

- Suppliers in the area of materials procurement. 
Since the Internet is a worldwide system for exchanging and distributing free-format information, it is regarded as an ideal platform for building up Information Systems [19]. The growth and wide use of the Internet generally for electronic commerce and for communication provides a valuable tool in the areas of information sharing, file transfer, communication and reporting on associated tasks. A number of organizations have utilized the Internet in the management of construction projects, though empirical evidence is scarce.

\section{Framework Perspectives}

In recent years some attempts have been made to examine the strategic implementation and performance evaluation of IT in construction. Pena-Mora et al. [7] and Jung and Gibson [20] developed two independent frameworks, which comprehensively cover the strategic IT implementation and planning aspects, but failed to address the critical aspect of post-implementation performance evaluation. Based on a comprehensive literature review, Andresen et al. [21] presented a framework to be used in assessing ways in which IT can benefit business processes. The framework compares estimated potential benefits to actual measured benefits obtained from implemented IT tools. Although the framework captures the complete spectrum of efficiency, effectiveness and business process benefits derived from IT implementation, it provides no answer as to how to combine those three different types of benefits, and most importantly, fails to recognise the difference in perceptions of participants estimating benefits and those measuring them. A more recent framework was proposed to evaluate the informational (savings due to improved quality of project information), automational (savings due to productivity improvement and cost reductions) and transformational (value added through innovation) benefits of IT in construction [22]. Although this particular framework was mainly developed to swerve away from considering subjective benefits evaluation, it utilizes probabilistic modelling and simulation techniques, which are purely based on subjective data, to evaluate informational benefits. Moreover, the framework fails to consider the users perceptions of the IT-induced benefits derived from implemented IT projects. Another major shortcoming of this framework is ignoring the enablers (i.e. user resistance, training and technical support, management support, etc.) to achieving these desired benefits. 
A comprehensive review of the above frameworks and other related IT performance evaluation issues can be found in Hampson et al. [23], Stewart and Mohamed [24] and Duyshart et al. [25].

In the absence of an IT performance evaluation framework specifically designed for evaluating electronic data interchange, which is the focus of this paper, the authors' opted to adopt a questionnaire-based approach to evaluate project-specific use of web-based communication on a construction project. The questionnaire items were categorised into five (5) definable robust performance measurement perspectives, which were developed, based on a critical review of the IT 'business value' evaluation literature [26-29]. These perspectives are as follows:

4. Operational Perspective: The well-documented fragmented nature of the construction industry requires this perspective to go beyond an internal process focus and encompass the diverse processes involving other project participants. This perspective is mainly concerned with the integration of IT into the organisation and the role it plays in process coordination and integration between the organisation and its counterparts. The measurement and evaluation of the newly coordinated/integrated processes should yield useful data about the impact IT has on the productivity and efficiency of these processes.

5. Benefits Perspective: The generic term 'benefits' goes beyond traditional financial measures (ie. NPV, ROI, IRR) to encompass the many non-monetary or intangible benefits derived by IT implementation. This perspective investigates the link between IT implementation and associated tangible and intangible benefits experienced by the organisation. Tangible benefits might include time and cost savings, which are relatively easy to assess/measure. However, intangible benefits are more difficult to measure and typically include non-monetary elements [30].

6. User Orientation Perspective: The term 'user orientation' has been adopted for this perspective to include both the internal as well as external customers (users) that are actively using the IT application or its output. From the user's perspective, the value of the tool is based largely on the extent to which it helps the user do the job more efficiently and effectively. This perspective covers issues such as tool 
utilisation rate, availability of training and technical support and satisfaction with the tool. New IT applications, not embraced by the user, will obviously fail to provide value to the organisation.

0. Strategic Competitiveness Perspective: This perspective differs from the 'benefits' perspective by focusing on the long-term strategic goals of the organisation and how the newly implemented technology creates competitive advantage for the future eg. potential for global cooperation, enhancing organisational image, and attracting more sophisticated clients. This perspective is perhaps the most difficult to quantify but has the greatest potential in the information era. Strategic competitiveness is representative of management's ability to instil the necessary cultural change to embrace innovative technology. Employees with the ability to adapt to an ever-changing work environment will be more receptive to new IT applications, which improve operational efficiency.

0. Technology/System Perspective: In addition to the above four perspectives, the technology/system perspective was included to encourage focusing on the technical elements of the IT being implemented by the organisation. This perspective refers to the non-people side of the technical system (i.e., hardware and software). This perspective covers issues such as tool performance, reliability, availability, security and suitability to the application/process.

\section{Developing Questionnaire Items}

Building on the above description, the framework should utilise project-, tool- and process- specific IT questionnaire items designed to reflect the particular aspects where IT implementation can improve projectbased processes performance. For evaluating the web-based communication system under investigation, potential indicators were initially extracted from general management, construction management and IT literature [5,30-34]. The outcome of this review has led to a list containing a large number of potential items, for each perspective, deemed to be applicable in measuring IT-induced performance. Using industry input, a further screening of this comprehensive list was conducted to ensure validity, reliability and significance of questionnaire items [10]. This has led to two distinct groups of items. The first of these is objective whereas 
the second is a subjective group of twenty-seven items (see Table 1). The latter is the focus of this paper. Below is the rationale for selecting subjective questionnaire items for each perspective.

\subsection{Operational perspective}

To meet operational objectives and clients expectations, organisations must identify key business processes at which they excel. These processes are the mechanisms through which IT-induced performance improvements are achieved. For example, Atkin [35] revealed that project teams reported enhanced communication and coordination by applying IT to support integration. Tucker et al. [10] suggest that IT can significantly improve document transfer and handling through web-based technology. Aouad [36] also supports this view. Instantaneous document transfer proved beneficial in terms of faster decision-making, quality improvements, cost savings and improved project team dynamics [37]. Baldwin et al. [38] suggest that IT applications and tools are essential to establish alliance relationships between project participants.

\subsection{Benefits perspective}

As mentioned earlier, strict economic principles such as ROI and NPV are partially useful for evaluating the benefits derived from IT investments. However, they fail to account for intangible benefits that are also important to IT measurement and evaluation. Intangible IT-induced benefits on construction projects typically include streamlined processes, decreased errors and client satisfaction. IT applications and tools can reduce the project cost and time overruns resulting from the current less than optimum communication and information management process [39]. Researchers recognise that process re-engineering is imperative to streamline existing processes before IT investments generate substantial value [40-42]. Walker and Rowlinson [43] highlight the potential for increased client satisfaction through web-based communications by providing instantaneous project information to clients.

\subsection{Technology/system perspective}


The appropriateness, efficiency and effectiveness of the implemented technology/system affect the performance of the remaining perspectives of the framework. This perspective is focused on the quality of the technology/system and includes technically-focused indicators such as response time, down time, responsiveness, functional integrity, relevancy of output, secureness and user-friendliness [44]. Flanagan et al. [2] studied small and medium sized contractors and builders and concluded that construction contractors still rely on personal contact, telephone and paper due to the nature of how the industry operates reflecting the fact that there are concerns as to the awareness, appropriateness, reliability and security of implemented IT tools. Jung and Gibson [20] identified computer system appropriateness as a key measure for planning computer-integrated construction.

\subsection{Strategic competitiveness perspective}

This perspective incorporates terminology and concepts such as future readiness, business competitiveness and innovation. According to Aouad [36], little regard has been given to the future potential of IT within the construction industry. Betts and Ofori, [45] suggested that IT offers opportunities as strategic weapons to gain competitive advantage and develop new business. Also, leading organisations adopting innovative IT are more likely to be more active in enhancing their organisation's image in domestic and international markets [46]. Clearly, the ability of IT to deliver quality services in the future will depend on the preparations that are made today and tomorrow.

\subsection{User orientation perspective}

Implemented IT projects will fail to be utilized effectively unless the user embraces them. This perspective captures the ability of the organisation to provide an adequate level of IT training and support to users. Previous research suggests that an organisation's failure with IT is primarily attributable to not meeting user expectations, which underlines the significance of the soft human and organisational issues involved with IT [8]. Clarke and Clarke [47] investigated the efficiency of IT training and concluded that training and human 
relations were important elements for achieving effective IT implementation. Therefore, the user orientation perspective is a key component of the framework.

\section{Case Study}

\subsection{Survey method}

In order to evaluate the performance of the web-based system used, for the first time, to instantly share, visualise and communicate project information between project participants, the above mentioned questionnaire items were used to develop a questionnaire to elicit information about the extent to which each item was achieved (see Table 1). Near completion of the project, the questionnaire was administered to 42 project participants [10]. A Likert-type scale was employed to access responses. This scale ranged from $1=$ “low/strongly disagree” to 5 = "high/strongly agree".

\subsection{Data Analysis}

To provide an initial assessment of the 27 items in the questionnaire, mean ratings and standard deviations were calculated for all responses. The raw scores of the responses are summarised in Table $\mathbf{1}$. The higher the mean the higher the degree of IT-induced performance improvement for the particular performance item. Prior to correlation and factor analyses, analysis of variance (ANOVA) was performed to test whether the mean values of each item were equal for each group of respondents: Management, designers and administrators. This helped clarifying whether or not the opinions of these three groups were the same for the 27 items dealt with in the survey. The results suggest a consensus between the three groups in relation to all items covered in the survey, with the exception of one issue ie. Q18: the user-friendliness of the web-based system. A high degree of difference of opinion between administrators and the other two groups seems to exist for this item. The explanation that could be offered here is that administrators might have experienced some difficulty in adapting to this new system due to unfamiliarity with its potential scope, and unlike designers and managers, that have more exposure to less user-friendly computer-based applications. In 
summary, since there was minimal bias between project participant groups the data was deemed appropriate for statistical analysis as one sample.

\section{(INSERT TABLE 1 HERE)}

Bivariate correlation was undertaken with all the questionnaire items and the results showed two items that were highly correlated. Malhoutra [48] states "if multicollinearity in the predictor variables exists, there is no unambiguous measure of the relative importance of the predictors in discriminating between the groups". When there is a high degree of correlation between some of the independent items in the data, interpretation of the results is difficult. This is because one item has assumed all the discriminating power of the other correlated item. As a result, interpretation of the results should be done with considerable caution.

Bivariate correlation showed that two items (Q5 \& Q6) elicit similar responses. The two items that are related to document management were found to be highly correlated. Consequently, it seems reasonable to delete question Q6, and leave the effect of records management to be taken up by Q5, which acts as a surrogate item and represents the combined effects of both items.

A principal component factor analysis followed by a varimax rotation was then undertaken on the remaining 26 items to determine the underlying perspectives of IT performance. The data were deemed to be appropriate for the analysis by exceeding the 0.50 threshold level, as indicated by the Kaiser-Meyer-Olkin measure of sampling adequacy value of 0.59 [49]. The initial analysis using SPSS V10.0 yielded a fivefactor solution, which accounted for 68 percent of the variance (see Table 2). However, the interpretability of the solution was rendered problematic because of one complex item, which loaded on three factors. Item Q17: secure against unauthorised use was found to be equally diffused over factors 2,3 and 5 with a loading value less than 0.4 in each of these factors. Due to the problematic nature of this item, it was removed from further analysis. It is worth noting here that although this empirical investigation warranted the removal of this indicator, the authors contend that IT security is an important factor that cannot be ignored. Further, construction research shows that security can be of concern to IT users [43]. 
(INSERT TABLE 2 HERE)

A subsequent analysis of the remaining 25 items yielded five factors with eigenvalues greater than one, which together accounted for 69 percent of the explained variance. Table 3 details factor loadings, explained variance, eigenvalues and Cronbach's $\alpha$ for the five factors. As can be seen, all analysed items have loadings greater than the minimum value of 0.4 suggested by Hair et al., [49] and were selected to define the five factors (perspectives). Cronbach’s Alpha for individual factors ranged from 0.71 to 0.89 , indicating adequate internal consistency [50].

(INSERT TABLE 3 HERE)

\section{Users' Perceptions of Web-based Tool's Performance}

Using the mean responses for each item in Table 3, an overall score defined on a scale from 0 to $100 \%$ can be calculated for each perspective of the framework. For example, the overall score for the operational perspective is calculated by the summation of mean scores for indicators OP1 to OP7 divided by the total possible maximum score for the seven indicators ie. OP1 $+\ldots+$ OP7 $=(3.81+3.81+3.79+3.21+4.12+$ $3.69+3.33) /(7 \times 5)=0.74=74 \%$. Each perspective's overall score was plotted on a spider diagram (see Figure 1). Scores for the five perspectives rated as follows (1) Operational: 74\%; (2) Benefits: 65\%; (3) Technology/System: 73\%; (4) Strategic Competitiveness: 69\%; and (5) User Orientation: 55\%. For the purpose of this paper, each perspective was assumed to contribute evenly to the overall performance of the IT tool. Using this approach, an overall performance score of $68 \%$ was calculated for the IT tool used on this particular project. It is worth pointing out, that organisations should individually weight the five perspectives to suit their specific goals and objectives. For example, organisations seeking competitive advantage through innovative use of the IT would assign a high weighting to the 'strategic competitiveness' perspective. 
Another advantage of the spider diagram is its ability to reflect areas where organisational efforts are needed to improve the utilisation of the IT tool, under investigation, to its maximum potential.

The performance baseline scores established for the IT tool used on this construction project can be utilised to assess any performance improvements on future construction projects. Considering a hypothetical example, performance scores for each of the five perspectives for a 'new' construction project undertaken by the organisation was obtained (see Figure 1). The overall performance score was calculated to be $74 \%$ for the 'new' construction project. Performance improvement can be evaluated by comparing the 'benchmark' score obtained on this project to the 'new' project score. A performance improvement score of 6\% (ie. 74\% 68\%) was calculated for this illustrative example. This procedure provides construction organisations with a simple, yet effective means to evaluate IT-induced performance improvement.

\section{Figure 1 Spider diagram showing the average score of each framework perspective (INSERT FIGURE 1)}

\section{Work in Progress}

Although only subjective items for evaluating IT-induced improvement have been reported herein, work-inprogress by the authors has incorporated objective (quantitative) measures in each perspective to enhance the applicability of the proposed framework. These measures, which are linked through cause-and-effect relationships across the five perspectives, should provide organisations with insights into the roles played by enablers as well as barriers to achieve maximum benefits from IT implementation on construction projects. Providing a mix of objective and subjective measures would definitely make the proposed framework more attractive to adopt. Also, research work is underway to examine the relative importance of roles played by individual perspectives in estimating the overall success or otherwise of the implemented IT tool. Subsequent objective IT evaluation will be reported in future publications.

\section{Conclusion}


With the combination of increasingly complex building types, growing number of outsourced project participants, tightly programmed fast-track construction methods, and a globally competitive marketplace, the ability to deliver profitable projects on time and within budget is becoming a significant challenge. Without the effective use of IT to facilitate the process of information management amongst project teams, it is unlikely that major improvements to the delivery process will eventuate by continuing to use traditional processes. This paper has sought to emphasise the importance of a structured evaluation process to manage and continually monitor the performance of implemented IT investments. The developed framework goes beyond traditional evaluation approaches by accommodating the wider intangible human, organisational and strategic benefits of IT investments.

The case study applied the framework on a large multi-disciplinary construction project to evaluate the ITinduced performance improvement on a construction project resulting from the implementation of a webbased communication tool. The case study served two primary purposes. Firstly, to refine the developed IT performance perspectives and indicators through statistical analysis. Secondly, to create a baseline against which future performance measurement can be benchmarked.

Examining various indicators individually, project participants agreed that the IT tool made a positive contribution to operational indicators such as document transfer and handling (OP5 $=4.12$ ), enhanced coordination and communication between project participants $(\mathrm{OP} 1=3.81)$, and reduced response time to answer queries $(\mathrm{OP} 2=3.81)$. Overall, they perceived the operational perspective $(74 \%)$ as being where the web-based system derived the most value. However, project participants were not overly satisfied with the level and frequency of IT training $(\mathrm{UO} 1=2.52)$ and support $(\mathrm{UO} 2=2.98)$ provided. This suggests that mean scores for indicators within the other four perspectives could have been higher if project participants were adequately trained, encouraged and supported throughout implementation. 
Since this was the first time the web-based system was used in a project environment, not all the capabilities of the system were utilised by project participants, perhaps limiting their perceptions as to the full potential of the system. Future applications should alleviate this problem. As a final note, construction organisations are encouraged to lay the foundations for a performance measurement and management culture, by actively seeking to evaluate and quantify the value IT generates.

\section{References}

[0] Z.M. Deng, H. Li, C.M. Tam, Q.P. Shen, P.E.D. Love, An application of internet-based project management system, Automation in Construction 10 (2001) 239-246.

[0] R. Flanagan, I. Ingram, L. Marsh, A bridge to the future: Profitable construction for tomorrow's industry and it’s customers (Thomas Telford, Springfield, 1998).

[0] A.N. Baldwin, A. Thorpe, C. Carter, The use of electronic information exchange on construction alliance projects, Automation in Construction 8 (1999) 651-662.

[0] B-C. Bjork, Information technology in construction: domain definition and research issues, International Journal of Computer Integrated Design and Construction 1(1) (1999) 3-16.

[0] M. Betts, Strategic Management of IT in Construction (Blackwell Science, Oxford, 1999).

[0] B.L. Atkin, J.V.L. Gravett, Benchmarking Best Practice Report: Integrated Project Information (Summary Report for the Construct IT Centre, Salford, 1999).

[0] F. Pena-Mora, S. Vadhavkar, E. Perkins, T. Weber, Information technology planning framework for large-scale projects, Journal of Computing in Civil Engineering (ASCE), October (1999) 226-237. 
[11]Z. Irani, P.E.D. Love, The propagation of technology management taxonomies for evaluating investments in information systems, Journal of Management Information Systems 17(3) (2001) 161-177.

[12]L. Uchitelle, We're leaner, meaner and going nowhere faster, in: New York Times, Section 4: May 12 (1996) 1-4.

[13] S.N. Tucker, S. Mohamed, D.R. Johnston, S.L. McFallen, K.D. Hampson, Building and construction industries supply chain project, in: CSIRO Confidential Report, BCE Doc. 01/124, June, (CSIRO, Brisbane, 2001) 56p.

[14]D.R. Shoesmith, Using Internet as a dissemination channel for construction research, Construction Information Technology 3(2) (1995) 65-75.

[15] M. Hannus, A. Watson, B. Luiten, M. Deguine, G. Sauce, T. Van Rijn, ICT tools for improving the competitiveness of the LSE Industry, Journal of Engineering Construction and Architectural Management 6(1) (1999) 30-37.

[16] N. Fisher, L.Y. Shen, Information Management within a Contractor (Thomas Telford, London, 1992).

[17] T. Froese, J. Rankin, K. Yu, Project management application models and computer-assisted construction planning in total project systems, International Journal of Construction Information Technology 5(1) (1997) 39-62.

[18] G.T. Luiten, F.P. Tolman, M.A. Fischer, Project modelling to integrate design and construction, Computers in Industry 35(1) (1998) 13-29.

[19] T. Cornick, Quality Management for Building Design (Butterworth Architecture Management Guides, London, 1996). 
[0] M. Kagioglou, R. Cooper, G. Aouad, J. Hinks, M. Sexton, D. Sheath, Final Report: Process Control (University of Salford, Salford, 1998).

[0] R. McCaffer, T.M. Hassan, Changes in large scale construction arising from ICT developments, in: Proceedings of the Millennium Conference on Construction Project Management, Hong Kong, October 2000, 8-15.

[0] M. Adcock, EDI in Construction: A Guide to Introducing Electronic Data Interchange Between Companies (Business Round Table, London, 1996).

[0] Y. Jung, G.E. Gibson, Planning for computer integrated construction, Journal of Computing in Civil Engineering (ASCE) 13(4) (1999) 217-225.

[0] J. Andresen, A. Baldwin, M. Betts, C. Carter, A. Hamilton, E. Stokes, T. Thorpe, A framework for measuring IT innovation benefits, Electronic Journal of Information Technology in Construction (www.itcon.org) 5 (2000) 57-72.

[0] L. Marsh, R. Flanagan, Measuring the costs and benefits of information technology in construction, Journal of Engineering, Construction and Architectural Management 7(4) (2000) 423-435.

[0] K.D. Hampson, R.J. Peters, D.H.T. Walker, S.N. Tucker, S. Mohamed, M. Ambrose, D. Johnston, Case study of the Acton Peninsula development (Government Research Report, Dept of Industry, Science and Resources, Commonwealth of Australia Government, Canberra, 2001).

[0] R.A. Stewart, S. Mohamed, Utilizing the balanced scorecard for IT/IS performance evaluation in construction, Journal of Construction Innovation 1(3) (2001) 147-163. 
[28]B. Duyshart, S. Mohamed, K.D. Hampson, D.H.T. Walker, Enabling improved business relationships how information technology makes a difference, In: Procurement strategies: a relationship based approach, Chapter 6, D.H.T. Walker and K.D. Hampson (eds) (Blackwell Publishing, Oxford, 2002).

[29] M. Parker, R. Benson, H. Trainer, Information economics: Linking business performance to information technology (Prentice Hall, Englewood Cliffs, 1988).

[30] W.H. Delone, E. McLean, Information system success: the quest for the dependent variable, Information Systems Research 3(1) (1992) 60-95.

[31] J.G. Priest, L. Doukas, N. Blaikie, Investigation of factors that strongly influence the outcomes of information technology (IT) systems investments, in: Proceedings of the IEEE Engineering Management Conference, 1995.

[32] M.C. Cronk, E.P. Fitzgerald, IS business value: operationally defining the dependent variable, in: Proceedings of the Australian Conference on Information Systems, Sydney, Australia, October 1998.

[33] V. Serafeimedis, S. Smithson, Information systems evaluation in practice: a case study of organisational change, Journal of Information Technology 15(2) (2000) 93-106.

[34] M. Parker, Strategic Transformation and Information Technology (Prentice Hall, Upper Saddle River, 1996).

[35] J. Ballantine, M. Bonner, M. Levy, A. Martin, The 3-D model of information systems success: the search for the dependant variable continues, Information Resources Management Journal 9(4) (1996) 514. 
[36] T. Saarinen, An expanded instrument for evaluating information system success, Information and Management 31(2) (1996) 103-118.

[0] J. Ballantine, S. Stray, Information systems and other capital investments: Evaluation practice compared, Logistics and Information Management 12(1-2) (1999) 78-93.

[0] B.L. Atkin, Measuring information integration in project teams, in: Proceedings of CIB-W78 Workshop, Vancouver, Canada, May 30 - June 3, 1999.

[0] G. Aouad, Managing construction information effectively using integrated databases, in: Proceedings of CIB-W65 Workshop, Vol. 3, Glasgow, UK, 1996.

[0] C.J. Anumba, N.F.I. Evbuomwan, A taxonomy for communication facets in concurrent life-cycle design and construction, Journal of Computer-Aided, Civil and Infrastructure Engineering 14(1) (1999) 37-44.

[0] A.N. Baldwin, A. Thorpe, C. Carter, The construction alliance and electronic information exchange: A symbolic relationship, in: Proceedings of CIB-W65 Workshop, Vol. 3, Glasgow, UK, 1996.

[0] P.E.D. Love, C. MacSporran, S.N. Tucker, The application of information technology by Australian contractors: towards process re-engineering, in: The International Group on Lean Construction (IGLC) 96, Fourth Annual Conference, Birmingham, UK, August 26-27, 1996.

[0] C.E. Clark, N.C. Cavanaugh, C.V. Brown, V. Sambamurthy, Building change-readiness capabilities in the IS organisation: Insights from Bell Atlantic experience, MIS Quarterly 21 (1997) 425-455.

[0] C.V. Brown, S.L. Magill, Reconceptualizing the context-design issue for the information systems function, Organisation Science 9 (1998) 176-194. 
[0] S. Mohamed, What do we mean by construction process re-engineering? International Journal of Computer Integrated Design and Construction 1 (1999) 3-9.

[0] D.H.T. Walker, S. Rowlinson, Procurement and the world wide web (www) - presenting company capabilities for selective tendering, in: Proceeding of the CIB-W55 and W65 Joint Triennial Symposium, Cape Town, South Africa, September 5-10, 1999.

[0] J. Ward, P. Taylor, P. Bond, Evaluation and realisation of IS/IT benefits: an empirical study of current practice, European Journal of Information Systems 4 (1996) 214-225.

[0] M. Betts, G. Ofori, Strategic planning for competitive advantage in construction: the institutions, Construction Management and Economics 12 (1994) 203-217.

[0] R.A. Stewart, S. Mohamed, Using benchmarking to facilitate strategic IT implementation in construction organisations, Journal of Construction Research 2 (2001) 25-33.

[0] P. Clarke, J. Clarke, Analysis of phenomenological perceptions of effectiveness of information technology in computerised technology and computerised maintenance management, in: Proceedings of the CIB-W78 Workshop, Vancouver, Canada, May 30 - June 3, 1999.

[0] N.K. Malhotra, Marketing research: An applied orientation (Prentice Hall, New Jersey, 1993).

[0] J.F. Hair, J.F. Anderson, R.L. Tatham, Multivariate data analysis, $5^{\text {th }}$ edition (Prentice Hall, Upper Saddle River, 1998).

[0] R.M. Kaplan, D.P. Saccuzzo, Psychological testing: Principles, applications and issues (Brooks/Cole, California, 1993). 
Table 1 Summary of responses

\begin{tabular}{llcc}
\hline \hline Item & Item Description & Mean & Std dev. \\
\hline \hline & The IT tool has: & 3.81 & 0.94 \\
Q1 & Enhanced coordination between project participants & 3.81 & 0.83 \\
Q2 & Reduced response time to answer queries & 3.79 & 0.78 \\
Q3 & Established and supported the project organisation & 3.21 & 0.90 \\
Q4 & Empowered participants to make decisions & 4.12 & 0.67 \\
Q5 & Facilitated document transfer and handling & 3.98 & 0.84 \\
Q6 & Helped keeping and updating records & 3.69 & 1.00 \\
Q7 & Enabled immediate reporting and feedback & 3.33 & 0.87 \\
Q8 & Helped Identifying errors and/or inconsistencies & & \\
\hline & The IT tool has: & 3.60 & 1.11 \\
Q9 & Enabled realising cost savings & 3.48 & 1.09 \\
Q10 & Improved document quality & 2.88 & 1.09 \\
Q11 & Decreased number of design errors & 2.81 & 1.09 \\
Q12 & Decreased number of Requests for Information (RFI's) & 3.14 & 1.07 \\
Q13 & Led to more satisfied customers/users & 3.67 & 1.10 \\
Q14 & Enabled streamlining of processes & 3.83 & 1.17 \\
Q15 & Improved computer literacy & & \\
& In my opinion, the IT tool has been: & 3.67 & 0.82 \\
Q16 & Reliable throughout the course of application & 3.62 & 1.19 \\
Q17 & Secure against unauthorised use & 3.62 & 0.76 \\
Q18 & User-friendly & 3.81 & 0.83 \\
Q19 & Appropriate for application/function & 3.64 & 1.34 \\
Q20 & Suitable for use on site & & \\
\hline & In my opinion, the IT tool has the potential to: & 3.36 & 1.14 \\
Q21 & Enhance my organisation's image in the industry & 2.95 & 1.13 \\
Q22 & Help attract more sophisticated clients & 3.60 & 1.29 \\
Q23 & Increase my organisation's capability for global cooperation & 3.57 & \\
\hline & My level of satisfaction with: & 1.06 \\
Q24 & The IT tool & 3.67 & 0.92 \\
Q25 & Level and frequency of training provided & 0.82 \\
Q26 & Level and frequency of technical support provided & \\
Q27 & The accuracy and quality of the output & & \\
\hline & & & \\
& & & \\
\end{tabular}


Table 2 Varimax factor loadings for the initial five-factor solution

\begin{tabular}{|c|c|c|c|c|c|}
\hline \multirow[t]{2}{*}{ Item } & \multicolumn{5}{|c|}{ Factor Analysis Components } \\
\hline & $\begin{array}{c}\text { Factor } 1 \\
\text { Operational }\end{array}$ & $\begin{array}{l}\text { Factor } 2 \\
\text { Benefits }\end{array}$ & $\begin{array}{c}\text { Factor } 3 \\
\text { Technology/ } \\
\text { System } \\
\end{array}$ & $\begin{array}{c}\text { Factor } 4 \\
\text { Strategic } \\
\text { Competitiveness } \\
\end{array}$ & $\begin{array}{c}\text { Factor } 5 \\
\text { User Orientation }\end{array}$ \\
\hline Q1 & $0.708 * *$ & 0.222 & 0.303 & 0.016 & -0.240 \\
\hline Q2 & $0.688 * *$ & 0.309 & 0.251 & -0.039 & -0.117 \\
\hline Q3 & $0.827 * *$ & 0.170 & 0.130 & -0.005 & 0.122 \\
\hline Q4 & $0.664 * *$ & 0.164 & -0.001 & 0.240 & 0.045 \\
\hline Q5 & $0.521 * *$ & 0.199 & 0.416 & 0.067 & -0.041 \\
\hline Q7 & $0.597 * *$ & -0.028 & 0.138 & 0.503 & -0.310 \\
\hline Q8 & $0.639 * *$ & 0.007 & 0.200 & 0.070 & 0.032 \\
\hline Q9 & 0.310 & $0.719 * *$ & 0.392 & 0.095 & -0.106 \\
\hline Q10 & 0.082 & $0.791 * *$ & 0.355 & 0.182 & 0.181 \\
\hline Q11 & 0.383 & $0.751 * *$ & 0.051 & 0.153 & -0.017 \\
\hline Q12 & 0.220 & $0.546 * *$ & 0.046 & 0.323 & -0.376 \\
\hline Q13 & 0.038 & $0.661 * *$ & 0.192 & 0.566 & 0.127 \\
\hline Q14 & 0.269 & $0.609 * *$ & 0.410 & 0.252 & -0.125 \\
\hline Q15 & 0.008 & 0.357 & 0.124 & $0.745 * *$ & 0.025 \\
\hline Q16 & 0.087 & 0.387 & $0.698 * *$ & 0.116 & 0.178 \\
\hline Q17 & 0.218 & $0.361 *$ & $0.341 *$ & 0.240 & $-0.382 *$ \\
\hline Q18 & 0.275 & -0.014 & $0.761 * *$ & -0.030 & -0.027 \\
\hline Q19 & 0.133 & 0.245 & $0.879 * *$ & 0.018 & 0.009 \\
\hline Q20 & 0.363 & -0.111 & $0.552 * *$ & 0.405 & -0.354 \\
\hline Q21 & 0.093 & 0.179 & -0.066 & $0.861 * *$ & 0.091 \\
\hline Q22 & 0.184 & 0.038 & 0.053 & $0.811 * *$ & 0.200 \\
\hline Q23 & 0.002 & 0.172 & 0.088 & $0.838 * *$ & 0.040 \\
\hline Q24 & 0.231 & 0.170 & $0.686 * *$ & 0.049 & -0.019 \\
\hline Q25 & -0.152 & 0.075 & 0.055 & 0.196 & $0.763 * *$ \\
\hline Q26 & 0.199 & -0.082 & 0.120 & 0.156 & $0.860 * *$ \\
\hline Q27 & 0.124 & 0.325 & $0.605 * *$ & 0.113 & 0.310 \\
\hline
\end{tabular}

* $\quad$ Variable is diffused over two or more factors

** Variable loads strongly into only one factor 
Table 3 Varimax rotated factor loadings for the five-factor solution

\begin{tabular}{|c|c|c|c|}
\hline Factor & Ref. & Items (identifying questions) & $\begin{array}{l}\text { Factor } \\
\text { Loading }\end{array}$ \\
\hline 1. Operational & OP1 & Enhanced coordination between project participants & 0.71 \\
\hline Variance $=15.7 \%$ & OP2 & Reduced response time to answer queries & 0.69 \\
\hline Eigenvalue $=3.94$ & OP3 & Established and supported the project organisation & 0.83 \\
\hline \multirow[t]{4}{*}{ Cronbach’s $\alpha=0.85$} & OP4 & Empowered participants to make decisions & 0.67 \\
\hline & OP5 & Facilitated document transfer and handling & 0.53 \\
\hline & OP6 & Enabled immediate reporting and feedback & 0.58 \\
\hline & OP7 & Helped Identifying errors and/or inconsistencies & 0.65 \\
\hline 2. Benefits & BE1 & Enabled realising cost savings & 0.72 \\
\hline Variance $=15.6 \%$ & BE2 & Improved document quality & 0.80 \\
\hline Eigenvalue $=3.91$ & BE3 & Decreased number of design errors & 0.75 \\
\hline \multirow[t]{3}{*}{ Cronbach’s $\alpha=0.89$} & $\mathrm{BE} 4$ & Decreased number of Requests for Information (RFI’s) & 0.55 \\
\hline & BE5 & Led to more satisfied customers/users & 0.66 \\
\hline & BE6 & Enabled streamlining of processes & 0.60 \\
\hline 3. Technology/system & TS1 & Reliable throughout the course of application & 0.71 \\
\hline Variance $=15.2 \%$ & TS2 & User-friendly & 0.75 \\
\hline Eigenvalue $=3.79$ & TS3 & Appropriate for application/function & 0.88 \\
\hline \multirow[t]{3}{*}{ Cronbach's $\alpha=0.84$} & TS4 & Suitable for use on site & 0.56 \\
\hline & TS5 & The accuracy and quality of the output & 0.69 \\
\hline & TS6 & The IT tool & 0.60 \\
\hline 4. Strategic Competitiveness & SC1 & Enhance my organisation's image in the industry & 0.86 \\
\hline Variance $=14.6 \%$ & SC2 & Help attract more sophisticated clients & 0.81 \\
\hline Eigenvalue $=3.64$ & SC3 & Increase my organisation's capability for global cooperation & 0.84 \\
\hline Cronbach's $\alpha=0.88$ & SC4 & Improved computer literacy & 0.74 \\
\hline $\begin{array}{l}\text { 5. User Orientation } \\
\text { Variance }=8.2 \%\end{array}$ & UO1 & Level and frequency of training provided & 0.78 \\
\hline $\begin{array}{l}\text { Eigenvalue }=2.06 \\
\text { Cronbach's } \alpha=0.71\end{array}$ & $\mathrm{UO} 2$ & Level and frequency of technical support provided & 0.85 \\
\hline
\end{tabular}




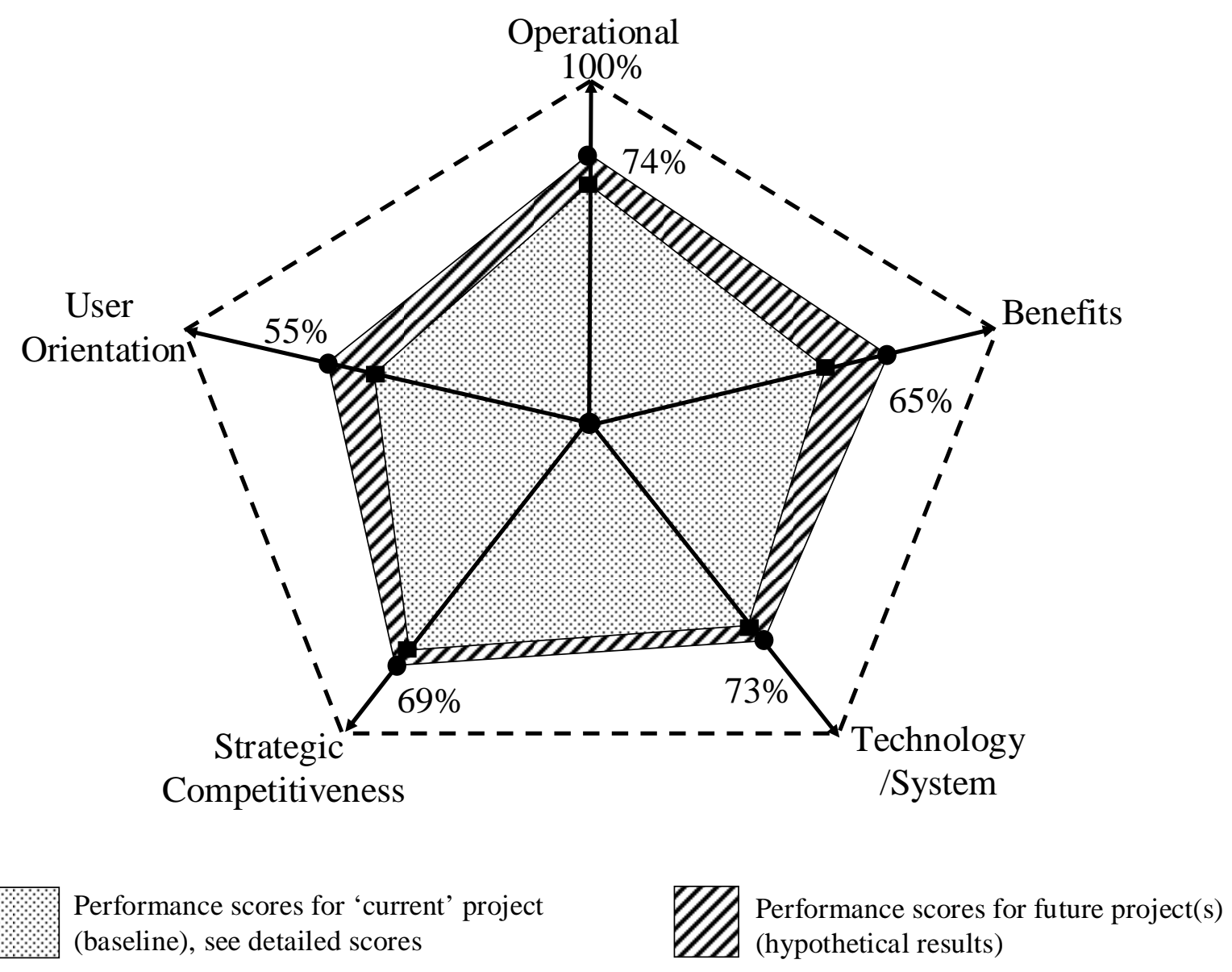

Figure 1 Spider diagram showing the average score of each framework perspective 